research funding, and consultancy and speaking fees from Sanofi-Aventis and Novartis.

\section{References}

ATKINSON, J. M., DOUGLAS-HALL, P., FISCHETTI, C., et al (2007) Outcome following clozapine discontinuation: a retrospective analysis. Journal of Clinical Psychiatry, 68, 1027-1030.

CIAPPARELLI, A., DELL'OSSO, L. BANDETTINI DI POGGIO, A., et al (2003) Clozapine in treatmentresistant patients with schizophrenia, schizoaffective disorder, or psychotic bipolar disorder: a naturalistic 48-month follow-up study. Journal of Clinical Psychiatry, 64 $451-458$.

DEVINSKY, O., HONIGFELD, G. \& PATIN, J. (1991) Clozapinerelated seizures. Neurology, $\mathbf{4 1}$ 369-371
DEVINSKY, O. \& PACIA, S.V. (1994) Seizures during clozapine therapy. Journal of Clinical Psychiatry, 55 (suppl B), 153-156

GREENWOOD-SMITHC, LUBMAN, D.I. \& CASTLE, D.J. (2003) Serum clozapine levels: a review of their clinical utility. Journal of Psychopharmacology, 17 234-238.

McEVOY, J. P., LIEBERMAN, J. A. SCOTT STROUP, T., et al (2006)

Effectiveness of clozapine versus olanzapine, quetiapine, and risperidone in patients with chronic schizophrenia who did not respond to prior atypical antipsychotic treatment. American Journal of Psychiatry, 163. $600-610$.
NATIONAL INSTITUTE FOR HEALTH AND CLINICAL EXCELLENCE (2002) Guidance on the use of newer (atypical) antipsychotic drugs for the treatmen of schizophrenia. HealthTechnology Appraisal No. 43. (http:// www.nice.org.uk/nicemedia/pdf/ ANTIPSYCHOTICfinalguidance.pdf).

PACIA, S.V. \& DEVINSKY, O. (1994)

Clozapine-related seizures: experience with 5629 patients. Neurology, 44, 2247-2249.

SAJATOVIC, M. \& MELTZER, H.Y. (1996) Clozapine-induced myoclonus and generalized seizures. Biological Psychiatry, 39, 367-370.

SILVESTRI, R. C., BROMFIELD, E. B. \& KHOSHBIN, S. (1998) Clozapineinduced seizures and EEG abnormalities in ambulatory psychiatric patients. Annals of Pharmacotherapy, 32, 1147-1151.

TANER, E., COSAR, B. \& ISIK, E. (1998) Clozapine-induced myoclonic seizures and valproic acid. International Journa of Psychiatry in Clinical Practice, 2, 53-55.

TAYLOR, D., PATON, C. \& KERWIN, R. (2007) The Maudsley Prescribing Guidelines (9th edn) Informa Healthcare.

TAYLOR, D. M. \& DUNCANMcCONNELL, D. (2000). Refractory schizophrenia and atypical

antipsychotics. Journal of Psychopharmacology, 14, 409-418

WELCH, J., MANSCHRECK, T. \& REDMOND, D. (1994) Clozapineinduced seizures and EEG changes. Journal of Neuropsychiatry and

Clinical Neurosciences, 6

Anna Sparshatt Senior Clinical Pharmacist, Eromona Whiskey Principal Clinical Pharmacist, * David Taylor Chief Pharmacist, Maudsley Hospital, Denmark Hill, London SE5 8AZ, email: David.Taylor@slam.nhs.uk

\title{
Referral patterns and acetylcholinesterase inhibitor prescribing for cognitive impairment (1999-2007): impact of NICE guidelines
}

\section{AIMS AND METHOD}

We hypothesised that the proportion of people referred to two outer London mental healthcare services for older people with cognitive impairment increased after the 2001 National Institute for Health and Clinical Excellence (NICE) guidelines for acetylcholinesterase (AChE) inhibitor use in Alzheimer's disease, but declined after the amended 2006 guidelines. We reviewed case notes for 546 individuals referred between 1999 and 2007.

RESULTS

The proportion of individuals with cognitive impairment referred increased between 1999 (56.1\%) and 2005 $\left(70.5 \%, \chi^{2}=5.4, P=0.02\right)$, as did the proportion prescribed $A C h E$ inhibitor
(0.8\% to $\left.16.1 \%, \gamma^{2}=27.5, P<0.001\right)$. There were no significant changes between 2005 and 2007.

\section{CLINICAL IMPLICATIONS}

The 2006 NICE amendment may have curbed the increase in psychiatric referrals and $\mathrm{AChE}$ inhibitor prescribing rates for people with cognitive impairment but so far these rates have not decreased.
In 2001, the National Institute for Health and Clinical Excellence (NICE) recommended the use of donepezil, galantamine and rivastigmine for people with Alzheimer's disease of mild and moderate severity, with a Mini Mental State Examination (MMSE) score above 12 (National Institute for Health and Clinical Excellence, 2001). These guidelines, together with other initiatives, were reported to have led to an increase in referrals to psychiatric services for cognitive impairment, which appeared to be caused by an increase in the number of people with mild impairment who were referred (O'Loughlin \& Darley, 2006). In November 2006, NICE revised their recommendations, indicating that prescription of acetylcholinesterase (AChE) inhibitors should be restricted to people with moderate Alzheimer's disease for reasons of costbenefit (National Institute for Health and Clinical
Excellence, 2006). A High Court challenge to this amendment in 2007 was unsuccessful.

This study is the first, to our knowledge, to explore the impact of the 2006 revised guidelines, and the considerable publicity surrounding them, on the rate of referral to psychiatric services of people with cognitive impairment and the proportion prescribed AChE inhibitors. It is possible that the revised guidance may have led to old age psychiatrists prescribing fewer AChE inhibitors, especially among people with mild dementia, and deterred general practitioners (GPs) from referring to mental health services people with mild cognitive impairment, if receipt of an AChE inhibitor had been an important reason for referral. We hypothesised that the proportion of people referred to two older people's community mental health services who had cognitive 
impairment and were prescribed an AChE inhibitor, increased in the years 1999 to 2005 but declined in 2005

original papers to 2007.

\section{Method}

The protocol of this study was first reviewed by the local research ethics committee, which viewed it as a service evaluation. As such, the study did not need ethical approval or patient consent.

We retrospectively analysed case notes for two community mental health teams for older adults for four 6-month periods (February to July) in 1999, 2001, 2005 and 2007. The study took place in an ethnically diverse, urban borough of London with a population of 21175 people aged over 65 years of age (Office for National Statistics, 2001).

All individuals referred by their GP and assessed in these periods were included.

The following information was extracted from case notes using a standardised form:

- age and gender

- diagnosis by the assessing psychiatrist

- MMSE score at assessment (MMSE is the most widely used measure of cognitive functioning, and adequate psychometric properties are reported; Folstein et al, 1975)

- whether an AChE inhibitor prescription was issued.

All data were analysed using SPSS version 14.0 for Windows and two-tail $\chi^{2}$-tests throughout. We used a significance level of $5 \%$ to test our main hypotheses, but $1 \%$ for other comparisons because of multiple testing. We reported descriptive statistics and then used $\chi^{2}$ to test our main hypotheses.

Using data from an initial pilot study, it was calculated that 88 new referrals at each time point would be required to detect a reduction of $20 \%$ in the proportion of people diagnosed with cognitive impairment, for a significance level of $5 \%$ and power of $80 \%$.

\section{Results}

Records of $546(100 \%)$ eligible individuals were reviewed. Their mean age was 79.6 years (s.d. $=7.9$ ), and 354 (64.8\%) were women. The number and proportion of those referred with cognitive impairment (including dementia and mild cognitive impairment) increased from $69(56.1 \%)$ in 1999 to 105 (70.5\%) in 2005 (Fig. 1; $\chi^{2}=5.4$, d.f. $=1, P=0.02$ ). There was also a non-significant increase in the number of such people between 1999 and 2001: from $69(56.1 \%)$ in 1999 to $90(64.7 \%)$ in 2001, $\left(\chi^{2}=2.0\right.$, d.f. $=1, P=0.15$ ). Between 2005 and 2007, the proportion of people referred who had cognitive impairment did not change significantly $\left(\chi^{2}=0.16\right.$, d.f. $\left.=1, P=0.69\right)$ and remained significantly higher than in 1999 and in 2001.

The number of referred people with cognitive impairment who were prescribed an AChE inhibitor increased significantly from $1(0.8 \%)$ in 1999 to 24 $(16.1 \%)$ in $2005\left(\chi^{2}=27.5\right.$, d.f. $\left.=2, P<0.001\right)$, but did not change significantly between 2005 and 2007: there were
24 such people in 2005 (16.1\%) and 23 in 2007 (17.0\%; $\chi^{2}=0.003$, d.f. $=1, P=0.96$ ) (Fig. 1). If people with diagnoses of alcohol-related or vascular dementia, or who had an MMSE documented as 12 or below were excluded (i.e. groups for whom AChE inhibitor prescription would not generally be recommended), then the number and proportions of people with cognitive impairment prescribed AChE inhibitors were $1(1.6 \%)$ in 1999 and 5 $(6.6 \%)$ in 2001, $24(30.0 \%)$ in 2005 and $23(28.0 \%)$ in 2007.

Alzheimer's disease was the most common diagnosis made in people referred with cognitive impairment, followed by vascular dementia (in 1999 to 2005) and mild cognitive impairment (in 2007) (Table 1). The frequency of mild cognitive impairment diagnoses increased over time, while the rate of other diagnoses did not change significantly. The mean MMSE score increased over the period of the study from 15.5 in 1999 to 20.5 in 2007 ( $F=4.8$, $P=0.003)$. The number of recorded MMSE scores also increased from 11 in 1999 to 97 in 2007.

\section{Discussion}

As hypothesised, the proportion of individuals with cognitive impairment and on AChE inhibitor medication referred to the services increased between 1999 and 2005, although it had not increased between 1999 and 2001. The increase in proportion as well as in absolute numbers suggests that this cannot be attributed simply to an ageing population. However, contrary to our hypothesis, there was no significant decrease in the proportion of those with cognitive impairment and prescribed AChE inhibitors referred between 2005 and 2007. Our study indicates that the increasing psychiatric referrals and $A C h E$ inhibitor prescribing rates that occurred between 1999 and 2005 did not continue in the two subsequent years, although they did not decrease as hypothesised. We found that less than a third of those who might have been theoretically eligible for an AChE inhibitor (based on diagnosis and MMSE score) were

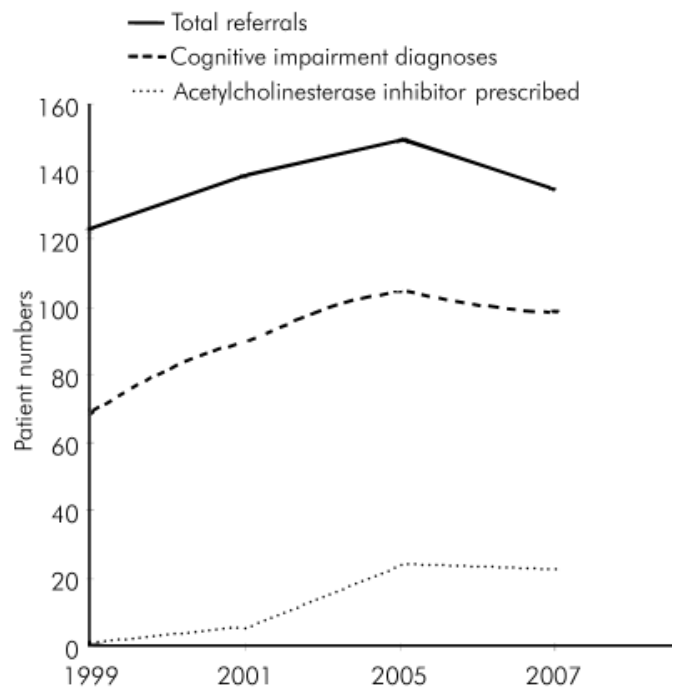

Fig. 1. Changes in the total number of referrals, cognitive impairment diagnoses and number of acetylcholinesterase inhibitors prescribed across the four sample periods. 


\begin{tabular}{|c|c|c|c|c|c|c|}
\hline & $\begin{array}{l}1999 \\
n(\%)\end{array}$ & $\begin{array}{l}2001 \\
n(\%)\end{array}$ & $\begin{array}{l}2005 \\
n(\%)\end{array}$ & $\begin{array}{l}2007 \\
n(\%)\end{array}$ & $\chi^{2}$ & $P$ \\
\hline Alzheimer's disease & $55(44.7)$ & $71(51.1)$ & $58(38.9)$ & $46(34.1)$ & 9.1 & 0.028 \\
\hline Vascular dementia & $7(5.7)$ & $12(8.6)$ & $23(15.4)$ & $16(11.9)$ & 7.6 & 0.056 \\
\hline Mild cognitive impairment & $4(3.3)$ & $4(2.9)$ & $13(8.7)$ & $23(17.0)$ & 23.6 & $<0.001$ \\
\hline Mixed dementia & $3(2.4)$ & $1(0.7)$ & $7(4.7)$ & $10(7.4)$ & 9.3 & 0.026 \\
\hline Alcoholic dementia & & $2(1.4)$ & $2(1.3)$ & $1(0.7)$ & & \\
\hline Lewy body dementia & & & $2(1.3)$ & $1(0.7)$ & & \\
\hline Dementia in Parkinson's disease & & & & $2(1.5)$ & & \\
\hline
\end{tabular}

original papers prescribed one. Possible reasons for this could be that patients did not agree to take the medication, were thought to be very unlikely to adhere to it or there were medical contraindications. We did not measure these factors in this study, so we also cannot rule out the possibility that some patients who could have benefited from these medications were not offered them. It is also likely that there are many people with dementia who may benefit from these drugs but they are not referred to services. We would therefore suggest that the reported plateau in rates of referral and prescription between 2005 and 2007 could indicate the 2006 NICE amendment has had an impact upon the earlier upward trend, in the proportion of people with dementia living in the catchment areas studied being actively managed through specialist referral and medication.

While earlier increases in referral rates and prescribing for people with cognitive impairment might have been curbed by the 2006 guidance, our findings did not indicate that GPs or psychiatrists have significantly changed their practice as a result. The mean MMSE score increased over the period of the study, suggesting GPs are referring people with dementia earlier in their illness. As the mean MMSE score of those referred has continued to increase and the proportion of people referred who receive an AChE inhibitor has not decreased, it seems likely that clinicians are making a clinical judgement regarding the target condition of moderate dementia rather than strictly adhere to MMSE score. This is concordant with the NICE guideline no. 42 for interpreting MMSE scores (National Institute for Health and Clinical Excellence, 2006b).

\section{Limitations}

The 6-month sample period analysed in 2007 commenced 3 months after the publication of the 2006 NICE guidance in November 2006. It could be argued that this is too brief a follow-up period to assess its impact on practice and that a decrease in referral rates and prescribing might yet occur. This is supported by our finding that although rates of referral were increased in 2001 compared with 1999, it was only when comparing the years 1999 and 2005 that we found a significant increase in referral rates. It takes time for clinicians to change their practice and for trusts to implement guidelines. This may be particularly so in this case as the new guidance was being challenged in the courts.
This study was based in one area of London, and may not reflect practice elsewhere in the UK. All the eligible case notes were available, but data regarding MMSE score are missing in a significant proportion of cases from earlier years, probably because an alternative cognitive measure was also used by the service at this time.

\section{Conclusions}

Whereas the proportion of individuals with cognitive impairment referred to the service and the rate of $\mathrm{AChE}$ inhibitor prescribing in the areas studied increased from 1999 to 2005, these rates were stable between 2005 and 2007. Our hypothesis that both rates would decrease owing to the 2006 NICE amendment was disproved. However, the change from a sharp increase in referral and prescribing rates to a plateau is notable, and may relate to the 2006 NICE amendment. Future research may indicate whether this was because referrers were awaiting confirmation of the guidelines from the court challenge.

\section{Declaration of interest}

None.

\section{References}

FOLSTEIN, M. F., FOLSTEIN, S. E. \& MCPUGH, P. R. (1975) 'Mini-Mental state': a practical method for grading the cognitive state of patients for the clinician. Journal of Psychiatric Research, 12, 189-198.

NATIONAL INSTITUTE FOR HEALTHAND CLINICAL EXCELLENCE (2001) Guidance on the Use of Donepezil, Rivastigmine and Galantamine for the Treatment of Alzheimer's Disease. Technology Appraisal Guidance, no. 19. NICE (http://www.nice.org.uk/guidance/ index.spp?action=bylD\&o=11413).

NATIONAL INSTITUTE FOR HEALTH AND CLINICAL EXCELLENCE (2006a)

Donepezil, Galantamine, Rivastigmine (Review) and Memantine for the
Treatment of Alzheimer's Disease. (Amended). NICE (http:// www.nice.org.uk/TA111).

NATIONAL INSTITUTE FOR HEALTHAND CLINICAL EXCELLENCE (2006b) Dementia. Supporting People with Dementia and their Carers in Health and Social Care. Reference CG42. NICE. OFFICE FOR NATIONAL STATISTICS (2001) Census 2001. (http:// www.statistics.gov.uk/census2001/ census2001.asp).

O'LOUGHLIN, C. \& DARLEY, J. (2006) Has the referral of older adults with dementia changed since the availability of acetylcholinesterase inhibitors and the NICE guidelines? Psychiatric Bulletin, 30, 131-134.
*Yogesh Ganeshalingam Specialist Registrar in Old Age Psychiatry, The Ladywell Unit, Lewisham High Street, South London and Maudsley NHS FoundationTrust, London SE13 6LW, email: yogesh34@hotmail.com, Claudia Cooper ResearchTraining Fellow, University College London, Department of Mental Health Sciences, Gill Livingston Professor of Psychiatry of Older People, University College London, Department of Mental Health Sciences 